BLS 32, No 1 2006. DOI: http://dx.doi.org/10.3765/bls.v32i1.3461 (published by the Berkeley Linguistics Society and the Linguistic Society of America)

\title{
Complementation by Construction
}

\author{
LAURA A. MICHAELIS \\ University of Colorado at Boulder
}

\section{Introduction}

Where does a verb's frame come from? According to an emerging consensus, the source is 'top down' scene construal rather than 'bottom up' lexical projection (Goldberg 1995, 2006, Kaschak \& Glenberg 2000, 2002, Partee \& Borschev 2007, Michaelis \& Ruppenhofer 2001). For example, as shown in (1-3), monovalent activity verbs like melt and sparkle, which have nothing intrinsically to do with location, can appear in the 'locative inversion' pattern, resulting in what Bresnan (1994) calls an 'overlay' of the locative-theme frame:

(1) In Maria's sticky hand melted a chocolate-chip ice-cream cone. (Birner \& Ward 1998: 193)

(2) And in this lacey leafage fluttered a number of grey birds with black and white stripes and long tails. (Levin \& Rappaport Hovav 1995: 226)

(3) Down at the harbor there is teal-green clubhouse for socializing and parties. Beside it sparkles the community pool. (Vanity Fair, 8/01)

In (1-3), the verb appears to describe what an entity is doing while in its location (melting, fluttering, sparkling) rather than a location state per se. Looking at a similar class of examples in Russian, Partee \& Borschev (2007:158) observe, "[o]ne could say that THING and LOC are roles of the verb [be] 'be', but it is undoubtedly better to consider them roles of the participants of the situation (or state) of existing or of being located". They go on to point out that the situation of existing involves not only a location state but also a particular perspective on that state, which they describe through an analogy to vision:

In an existential sentence, the LOC is chosen as the perspectival center; [the sentence asserts] of the LOC that it has THING in it. [...] An existential sentence is analogous to the way a security camera is fixed on a scene and records whatever is in that location. (Partee \& Borschev 2007:156) 
The security-camera metaphor aptly captures the stylistic effect of the locativeinversion pattern, but if we take it seriously we have to acknowledge that word meaning and syntactic meaning are a good deal more similar than traditional models of syntax would care to admit. Like a word, a syntactic pattern may be conventionally associated with a highly elaborated semantic frame, including a perspectival one. This is the view taken in construction-based syntax, as described by Goldberg $(1995,2002,2006)$ and others. Goldberg argues that argumentstructure patterns are constructions that denote situation types, and, therefore, that a verb's meaning and combinatory potential might change to fit the meaning of a given construction (Goldberg 1995, 2002, 2006, Michaelis \& Ruppenhofer 2001, Michaelis 2004). The construction-based model of argument structure proposed by Goldberg is integrative rather than projection-based: verb meanings are combined with construction meanings via a fixed number of semantic relations (including instance, means and manner) and the set of arguments licensed by the construction may properly include that licensed by the verb with which the construction is combined, as in (4-5):

(4) Most likely they were fellow visitors, just panting up to the sky-high altar out of curiosity. (L. Davis, Last Act in Palmyra, p. 28)

(5) When a visitor passes through the village, young lamas stop picking up trash to mug for the camera. A gruff 'police monk' barks them back to work. (Newsweek 10/13/97)

In (4), pant, a verb that otherwise licenses only a single argument, appears with two: it denotes the manner of the directed-motion event denoted by the construction. In (5), bark, another otherwise monovalent activity verb, has two additional arguments, a direct object and an oblique expression that indicates direction; in this context, the verb denotes the means by which a metaphorical caused-motion event, denoted by the construction, occurs. Rather than presuming a nonce lexical entry for pant in which it means 'move toward a goal while panting' and for bark in which it means 'move something from one place to another by barking', the constructionist presumes that the verbs in (4-5) mean what they always mean; arguments not licensed by the verb are licensed by the construction with which the verb combines. The constructional model of verbal syntactic variability is therefore more parsimonious that a lexicalist one: using a small number of argument-structure constructions, it limits the number of lexical entries needed for each verb.

The problem, however, is that the patterns that we use for creating phrases are not supposed to denote anything: they combine symbols rather than being symbols themselves. In other words, there is no compositional model of sentence meaning in which patterns of word combination are intrinsically meaningful. It is easy to understand why. In such models, sentences are licensed by rule-to-rule pairs, each of which consists of a context-free phrase-structure rule and a rule composing the semantics of the mother from the semantics of the daughters. By 


\section{Complementation by Construction}

changing the syntactic associations in a string of words one can change what the word string means, but not what the words in that string mean. An analogy to number sequences makes this clear: if we change the associations within an arithmetic sequence like $2 \times(3+4)$ so as to create the sequence $(2 \times 3)+4$, we change what the sequence denotes (from 14 to 10 ), but not what the numbers themselves denote. If the rules of syntactic combination do not add conceptual content to that contributed by the words, they should not be able to alter the combinatory potential of words.

In order to preserve a compositional model of sentence meaning, one might choose to view valence augmentation and other construal-based semantic effects on verbs as the products of lexical derivations that build up complex event structures from simpler ones. A model of this nature is proposed by Rappaport Hovav \& Levin (1998) (henceforth, RHL; see also Levin 2000). Unlike the construction-based model outlined above, the RHL model is based on lexical projection; as they put it: "Many aspects of the syntactic structure of a sentencein particular, the syntactic realization of arguments - are projected from the lexical properties of the verbs" (RHL: 97). Each of a verb's syntactic frames is associated with a distinct verb meaning, although every verb has one basic class membership. An implication of this model is that most verbs are polysemous, and many highly polysemous. Since RHL presume (in accordance with Pinker (1989) and others) that the only syntactically relevant component of verb meaning is aspectual meaning, the more aspectual representations a verb has the more syntactic variation it will display, and vice versa. To represent verb meaning and semantic operations on verb meaning, RHL propose (a) a set of Aktionsart-based schemas and (b) an operation that augments one such schema up to another one. Both the schemas and the augmentation operation are independently motivated; they appear, for example, in the transition network used by Moens \& Steedman (1988) to model aspectual type-shifts triggered by verb morphology. An example of one such shift is given in (6):

Mary was winning the race (when she was tripped by Zola).

In (6) we see that the progressive construction, which seeks a durative event as its daughter, can combine with a verb denoting a momentaneous event (win) and in so doing create a construal in which winning is preceded by a preparatory process. In terms of the Moens \& Steedman analysis, the progressive operator applies to the process phase of a culminated process (i.e., an accomplishment verb) that is derived from a culmination (i.e., an achievement verb) via augmentation (i.e., the addition of an activity representation or 'run-up process'). In the RHL model, verbs meanings are represented by the set of event-structure templates given in Table 1. In these representations, variables represent participants licensed by the event-structure template and capitalized italic terms enclosed in angled brackets represent idiosyncratic meaning components contributed by whatever verb combines with the template: 
Laura A. Michaelis

Table 1. Event Structure Templates (Rappaport Hovav \& Levin 1998)

\begin{tabular}{|l|l|}
\hline Aktionsart Class & Semantic Representation \\
\hline State & {$[\mathrm{x}<$ STATE $>$ e.g., shine } \\
\hline Activity & {$[\mathrm{x} \mathrm{ACT}<$ MANNER $>]$ e.g., skip } \\
\hline Achievement & {$[$ BECOME $[\mathrm{x}<$ STATE $>]]$ e.g., sink } \\
\hline Accomplishment & $\begin{array}{l}[[\mathrm{x} \text { ACT }<\text { MANNER }>] \text { CAUSE }[\text { BECOME y }<\text { STATE }>]]] \\
\text { e.g., build }\end{array}$ \\
\hline Accomplishment & {$[\mathrm{x}$ CAUSE $[$ BECOME y $<$ STATE $>]]$ e.g., break } \\
\hline
\end{tabular}

The valence of the verb may be lower than, higher than or equal to the number of argument slots in the template. Argument roles licensed by event-structure templates are referred to as structure participants while those licensed only by the verb are referred to as constant participants. According to the RHL account, activity verbs like chew or sweep are structurally intransitive: the second argument is a lexically licensed (constant) participant that does not fuse with any role of the activity event-structure template. RHL propose two argument-realization conditions on verb-template unification:

(7) a. Argument realization condition 1: Each structure participant must be realized by an XP.

b. $\quad$ Argument realization condition 2: Each XP must correspond to a subevent.

According to the condition given in (7a), which will be the focus of our attention in section 3.1, the second argument of an activity verb need not be realized, as in She chewed thoughtfully, while the second argument of an accomplishment verb must be realized: *They hammered flat. The RHL model preserves a strict version of compositionality, in which all conceptual content comes from the lexicon (Jackendoff 1997). In addition, the RHL model successfully factors syntax out of lexical entries, leaving the linking of participant roles to grammatical functions to morphosyntactic realization principles.

In this paper, however, I will discuss four classes of phenomena that suggest that verbs have the arguments that they do because they combine with constructions, not because they undergo semantic operations. I will also sketch a formal model of argument-structure constructions that captures the effects at issue. It is based on Sign-Based Construction Grammar (SBCG), a model developed by Fillmore et al. (forthcoming). I will also give some hints about how speech-error data lend support to constructionists. The linguistic phenomena that that I will discuss are as follows: 


\section{Complementation by Construction}

- Valence variation. The full range of verb-valence variability, including null complementation, cannot be described by augmentative operations on event structure of the type described by RHL.

- Weird sisterhood. Many verb frames specify sisterhood relations that are not predicted by the general-purpose constituency rules that combine heads and complements and heads and specifiers (known, respectively, as the Head-Complement Rule and the Specifier-Head Rule in Head-Driven Phrase Structure Grammar).

- Quantification of argument NPs. Stating constraints on quantifier scope in certain argument structures and explaining 'operator-free' nominal type coercion requires recourse to semantic frames, including quantifier frames.

- Paradigmatic effects. Certain constraints on argument realization appear to be the effects of one argument-structure construction overriding another (Zwicky 1994).

This paper will be structured as follows. In the following section, section 2, I will describe the foundations of SBCG. In section 3 I will discuss the four classes of phenomena enumerated above. In section 4 I will discuss a study of syntactic speech errors (Raymond 2000) which bolsters the claim that argument structure has a constructional basis.

\section{2. $\quad$ Sign-Based Construction Grammar (SBCG)}

In SBCG, as described by Fillmore et al. forthcoming, the basic objects of grammatical description are signs. A sign can be thought of as a node in a syntactic tree to which certain syntactic and semantic properties accrue. However, signs are more accurately described as feature structures that specify values for the attributes listed in (8-11):

(8) SYN is used to distinguish signs from one another. Its values are the features CAT and VAL(ENCE). The value of CAT is a syntactic category. The VAL feature represents the objects with which a given sign can combine. The VAL value of pronouns, proper nouns and most common nouns is an empty list. The VAL value of a verb is its combinatoric potential (e.g., the VAL value of a transitive verb is $<\mathrm{NP}, \mathrm{NP}>$ ).

(9) SEM describes the meaning of a sign; its values are the features INDEX and FRAMES. INDEX is the extension of a sign. The FRAMES feature is used to enumerate the predications that together specify the meaning of a sign. Among the frames that we will consider here are quantifier frames. For example, the meaning of the indefinite article $a$ in English is represented by means of an existential quantifier frame.

(10) FORM is used to specify the morphological properties of a given sign; the value of FORM is a (possibly empty) list of morphological entities.

(11) CONTEXT is used to specify features of context that are relevant to the interpretation and use of a given sign. 
The subtypes of sign are word, lexeme and phrase. Signs are licensed in two ways: by a lexical entry or by a construction. Accordingly, the grammar is viewed as consisting of a lexicon-a finite set of lexical descriptions (descriptions of feature structures whose type is either lexeme or word) and a set of constructions. Constructions build phrases (e.g., VP), words (e.g., the third-person singular form of the lexeme laugh) and lexemes (e.g., the causative lexeme corresponding to the inchoative lexeme boil); they do this by pairing a mother (MTR) with one or more daughters (DTR(S)). Put differently, constructions license constructs, linguistic objects consisting of a mother sign that dominates a daughter sign or signs. Figure 1 gives an example of a lexeme sign licensed by a lexical entry:

Figure 1. A Lexeme Sign

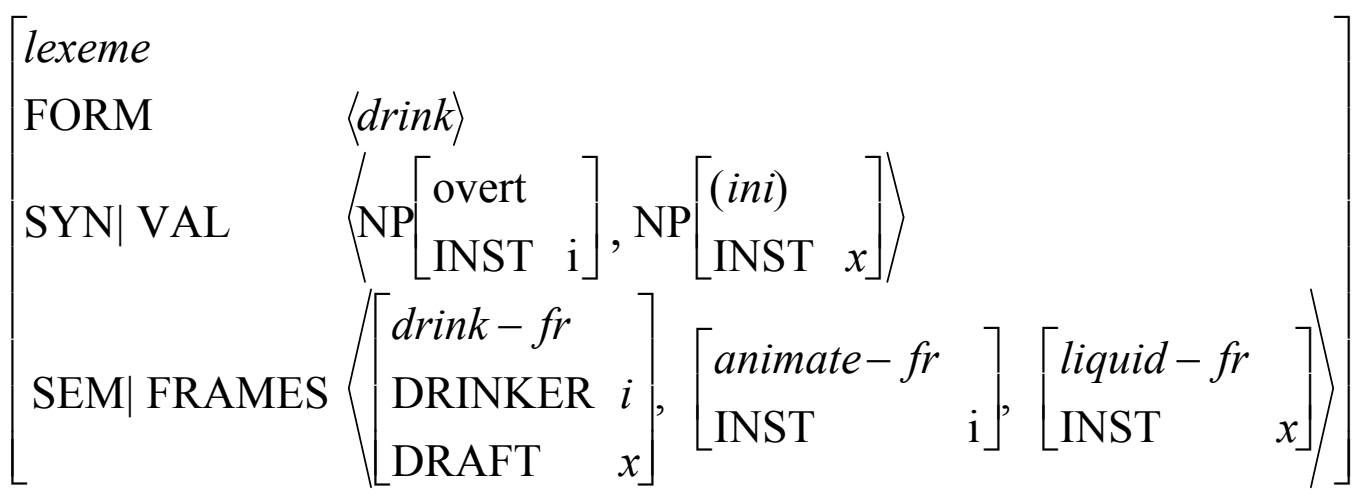

Figure 1 shows the English lexeme drink. The semantic properties of this lexeme are represented by a series of frames (e.g., the frame abbreviated as drink-fr). Frames are used to capture the requirement that the drinker be animate and that the consumed item be a liquid. The combinatoric properties of this lexeme are represented in its valence set, which includes two noun phrases - the first of which is coindexed with the 'drinker' participant in the drink semantic frame and the second of which is coindexed with the 'draft' participant in the drink frame. In addition, each valence member (or valent) is tagged with a feature that represents its instantiation properties: the first valent (the subject NP) is obligatorily instantiated, while the second is optionally null instantiated. As indicated, the second valent, when null instantiated, has an indefinite or, equivalently, existential interpretation. For example, sentence (12) means something like 'She drank some liquid substance from a plastic mug' (Fillmore 1986):

She drank from a plastic mug.

Figure 2 shows an inflectional construct licensed by the preterite construction, an inflectional construction that yields past-tense word forms of a verb lexeme (in this case, the lexeme laugh): 
Figure 2. An Inflectional Construct

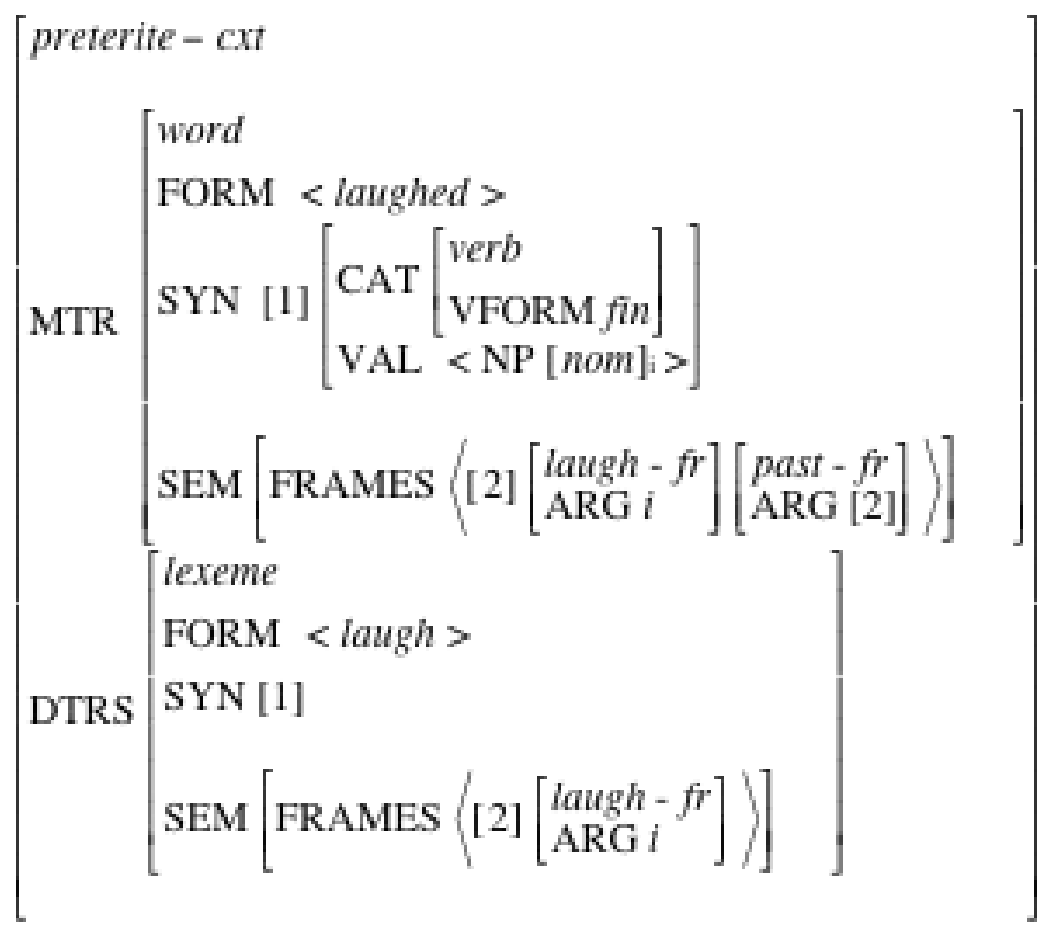

As an inflectional construct, this construct has a word as mother and a lexeme as daughter. The two occurrences of the tag [1] indicate that the SYN values of mother and daughter are identical. The past-tense meaning contributed by the construction is represented by the frame labeled past-fr in the mother's frame set. The single argument of this frame is the frame expressed by the verb lexeme (i.e., the laugh-frame), as indicated by the two occurrences of the tag [2] in the MTR.

Figure 3 shows a derivational construct of a type that will recur in our discussion of the quantification of argument NPs in section 3.3 below: 
Laura A. Michaelis

Figure 3. A Derivational Construct

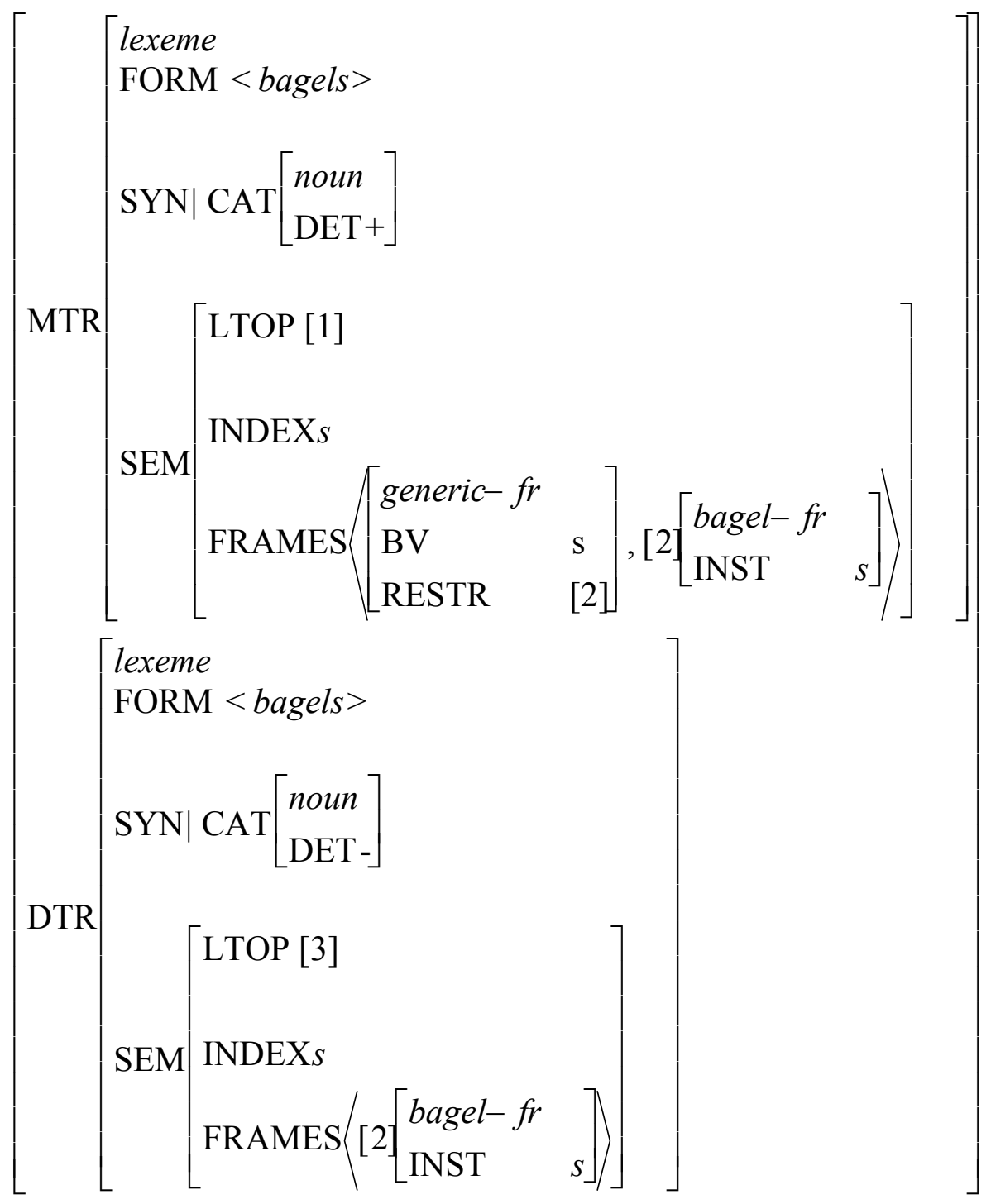

As in all derivational constructs, both MTR and DTR are lexemes. This particular construct is licensed by an English construction that Fillmore at al. (forthcoming) refer to as the Bare Noun Pumping construction. Bare Noun Pumping yields determinerless plural NPs capable of occupying grammatical-function positions, as in (13-14):

(13) Bagels are boiled.

(14) We served bagels.

Bare nominal expressions can serve as arguments insofar as they receive quantified interpretations. In (13), for example, the bare plural noun bagels is inter- 


\section{Complementation by Construction}

preted as expressing universal quantification over individuals of the type bagel, while in (14) it is interpreted as expressing an existentially quantified aggregate (in terms of Chierchia 2003). This means the bare nominal construction must supply a quantifier that would otherwise be supplied by a determiner. In fact, it appears that there must be two derivational constructions for bare plurals in English: one that provides for generic quantification of undetermined noun phrases and another that provides for existential quantification of undetermined noun phrases. The nominal construct in Figure 3 is licensed by the former construction; generic quantification is represented by the generic frame in the construction's MTR. The variable bound by the quantifier is represented as an argument of the quantifier frame (BV), as is the restriction on the range of the quantifier (RESTR). The use of the letter $s$ to represent the bound variable is intended to capture its ontological type (aggregate or, equivalently, sum individual).

What we have seen of the SBCG formalism in this section is, I hope, sufficient to convey the scope of the model: constructions are used not only to represent the composition of phrases but also the realization of morphological categories (inflectional constructions) and the addition of semantic features (derivational constructions). In earlier implementations of construction-based syntax (Goldberg 1995, Fillmore \& Kay 1993, Michaelis \& Ruppenhofer 2001), some constructions were portrayed as nonbranching - that is, they could consist of a single sign. In these approaches, argument-structure constructions were treated along the lines of schematic verb entries with which verbs unified in order to ensure grammatical expression of their semantic roles. In SBCG, by contrast, constructions are uniformly two-level; a construction describes a particular pairing of a mother sign with one or more daughter signs. SBCG combines the information expressed by signs through two mechanisms: embedding and unification (lexical entries unify with DTRS). Derivational constructions capture the effect of lexical rules without entailing conservation of thematic structure (Michaelis \& Ruppenhofer 2001: Chapter 1). As a partial description, a lexical entry permits multiple resolutions of unspecified feature values.

Common to all construction-based approaches is the idea that a verb's array of arguments, and the manner of each argument's realization, is determined by the argument-structure construction with which the verb combines. In this fundamental respect, construction-based models differ from lexicalist approaches like that of RHL, in which a verb's argument-licensing properties are determined by its Aktionsart representation and the morphosyntactic expression of its arguments by realization rules. The evidence to be reviewed in the following section will suggest that verb frames are not built up via operations on semantic structure but rather licensed by templates that constrain the syntax, semantics and discourse status of the arguments in quite detailed ways. 
Laura A. Michaelis

3. Evidence against an Aktionsart-driven Model of Argument Structure In this section, as promised, we will discuss four lines of evidence which converge to suggest that a verb's argument structure is determined by the construction with which it combines rather than by its Aktionsart structure, derived or otherwise. The evidence comes from valence variability (3.1), the special-case nature of rules governing syntactic sisterhood relationships (3.2), quantification of argument NPs (3.3) and paradigmatic effects, including blocking effects (3.4).

\subsection{Valence Variability}

The RHL model makes three predictions about null complementation (Ruppenhofer 2004: Chapter 4, this volume; Goldberg 2000, 2005). These are given in $(15-17)$ :

(15) As nonstructural arguments, the second arguments of bivalent state, achievement and activity verbs should always be omissible.

(16) Nonstructural participants are subject only to a recoverability condition based on prototypicality (RHL: 115); therefore all null complements should have existential (indefinite) interpretations.

(17) As structural arguments, patient arguments of accomplishment verbs should never be omissible.

Each of these predictions proves false. First, as shown in (18-20), it is not the case that all bivalent state, achievement and activity verbs allow omission of their second arguments:

(18) State: She resembles *(Aunt Molly).

(19) Achievement: I found *(my watch).

(20) Activity: We discussed *(the issue).

Second, as shown in (21-24), null instantiated second arguments of verbs in these Aktionsart classes do not necessarily have an existential interpretation; such arguments often have anaphoric interpretations:

(21) State: My feelings are similar (to yours).

(22) State: I remember (that).

(23) Achievement: I won (the race).

(24) Activity: I prepared (for that event) for weeks.

Third, as observed by Goldberg (2005), patient arguments of accomplishment verbs are in fact omissible, despite the fact that that these are ipso facto structural arguments in the RHL model: verbs of emission/ingestion like spit, swallow allow omission of their patient arguments (as in, e.g., He spit onto the sidewalk) and, as shown in (25-27), almost any verb, including an accomplishment verb, allows 


\section{Complementation by Construction}

existential null complementation of its second argument in an iterated-event context:

(25) Owls only kill (things) at night.

(26) China produces (things) and the US imports (things).

(27) She has never failed to impress (people).

Additional problematic aspects of the RHL model of null complementation are as follows. First, null-instantiated complements of nonverbal predicators, as exemplified by (28-30), simply remain unexplained, because such predicators presumably lack Aktionsart structure:

(28) Noun: Make me a copy (of that).

(29) Preposition: She walked over (here).

(30) Adjective: I'm taller (than you).

Second, as pointed out by Ruppenhofer (this volume), null-complementation affordances of verbs are affected by context; when a motion verb is interpreted as denoting a path shape rather than actual movement, it does not generally allow omission of its landmark argument:

Actual motion: Where did she cross (the road)?

Fictive motion: Where does Highway 42 cross *(Highway 287)?

Although fictive- and actual-motion verbs do differ aspectually (the former being stative and the latter dynamic), the null-complementation split in (31-32) is the reverse of the one predicted by the RHL model, which treats the second arguments of state verbs, but not accomplishment verbs, as omissible.

The flip side of valence reduction is valence augmentation, and this phenomenon too presents problems for an Aktionsart-driven model of argument structure. Recall from Table 1 that, in the RHL model, accomplishment verbs like break have the Aktionsart representation $x$ CAUSE [BECOME $y<$ STATE $>$ ]. Recall too principle (7b): Each XP must correspond to a subevent. Given these two conditions, we have no easy way to account for the well-formedness of (33-34):

(33) She crumbled the crackers into the soup.

(34) The snow broke the branches off the tree.

The above examples should be ungrammatical, because in each a directional expression (into the soup or off the tree) denotes a resultant state distinct from that entailed by the verb's Aktionsart representation (the resultant states of being crumbled and broken, respectively). These PPs therefore are XPs that do not correspond to a subevent, in violation of (7b). The facts in (33-34) are not, however, difficult for an integration-based model like Goldberg's to handle: the 
verb denotes the means by which a causation-of-motion event, denoted by the construction, occurs. For example, in (33), crumbling is construed as the means by which the crackers are moved from one location (the agent) to another (the soup). An additional fact that suggests the relative independence of Aktionsart and argument structure is brought out by Michaelis \& Ruppenhofer (2001) in their study of applicative formation in English and German: argument-structure patterns often underdetermine aspect. This is shown by (35) and its German translation (36):

They sailed the Caribbean in three months/for three months.

Sie besegelten die Karibik in drei Monate/drei Monatelang.

While one might be tempted to associate the applicative (locative object) pattern with accomplishment Aktionsart, insofar as the pattern implies 'affectedness', 'coverage' or 'saturation' of the location denoted by the object NP, the acceptability of both a durational adverbial (for three months, drei Monatelang) and a frame adverbial (in three months, in drei Monate) suggests that applicative verbs have both telic (accomplishment) and atelic (activity) construals. Whatever the meaning of the applicative pattern, it cannot be exclusively Aktionsart-based.

The constructional account of argument structure treats verb-valence variability as the product of constructional affordances rather than as following from a verb's semantic representation. It does not, for example, recognize a class of 'structurally intransitive' verbs; instead, it presumes a set of derivational constructions that license null instantiation of arguments. These constructions effectively remove arguments from a verb's valence list, while ensuring that the quantifier frame of the null-instantiated argument remains in the verb's argument-structure list. In SBCG terms, the MTR's semantic frames include the quantifier frame missing from the valence set of the DTR (Fillmore et al. forthcoming). Once we have such a construction, we can also use its FRAMES attribute to indicate whether a given null-instantiated argument is construed anaphorically, as in (2124), or existentially, as in (25-27). An example of such a construction is the one that Goldberg (2005) views as licensing existentially interpreted null-instantiated theme arguments of emission verbs, e.g., spit, sneeze. Evidence for such a construction comes from coercion phenomena involving verbs of vision:

(37) She frowned into the mirror.

(38) She glanced over her shoulder.

As semelfactive verbs, neither frown nor glance licenses a directional argument; it is only via combination with the construction that licenses an existentially construed null-instantiated theme argument that these verbs may be augmented up to causation-of-motion verbs. Such augmentation involves a metaphorical construal of vision involving an 'eye beam' that moves from one location (the perceiver) to another (the percept). What might seem paradoxical - that a 'subtraction' con- 


\section{Complementation by Construction}

struction here adds an argument (a directional expression) - makes perfect sense on the constructional account: the construction that licenses null complementation of theme arguments of verbs of emission denotes an event of transfer, and therefore licenses a trivalent transfer frame. In addition to capturing such coercion effects, null-complementation constructions enable us to account for override effects involving null complementation restrictions on verbs. While, as observed above, accomplishment verbs do not license null-instantiated theme arguments when construed episodically, they do when construed iteratively, as shown in (2527). This means that, as argued by Goldberg (2005) and Ruppenhofer (2004: Chapter 4), aspectual constructions like the existential perfect construction also carry constraints on argument instantiation, allowing indefinite null complementation in examples like (27). Constructions are exactly such complexes of syntactic and semantic constraints.

\subsection{Weird Sisterhood}

A number of argument-structure patterns involve sisterhood relations that are not licensed by the head-complement or specifier-head phrase-building rules. This suggests that argument licensing is not exclusively semantic, and that to describe argument licensing we need to include information about the syntactic categories of arguments. In this subsection, we will briefly look at three cases of weird sisterhood found in English: Nominal Extraposition, Just because and Hypotactic Apposition. Data are taken from two corpora of English telephone conversations that are available through the Linguistic Data Consortium (www.ldc.upenn.edu): the Switchboard corpus (sw) or the Fisher corpus (fe).

\subsubsection{Nominal Extraposition.}

In Nominal Extraposition, an exclamatory adjective, e.g., amazing, licenses an NP complement:

(39) I know it's just it's unbelievable the different things that are happening in America today. (sw03982B)

(40) I'll date myself a little bit but it it's remarkable the number of those things they need. (sw02392B)

(41) I know. I love that game. It's amazing the words they come up with. (fe_03_08039A)

The pattern exemplified in (39-41) is idiosyncratic in two respects. First, adjectives are not case assigners and should not therefore license non-oblique NP complements. Second, this NP complement is interpreted as denoting a scalar degree (Michaelis \& Lambrecht 1996). In (41), for example, the NP the words they come up stands in for a scalar expression like 'the number of words they come up with'. The fact that the complement of amazing in (41) has a scalar interpretation follows from the fact that (41) is an exclamation, but the pairing of an exclamatory adjective with an NP sister that denotes a degree, metonymically 
Laura A. Michaelis

or otherwise, requires a construction that provides for this syntax and this meaning.

\subsubsection{Just Because}

In the Just Because construction, a negated epistemic verb, typically mean, licenses a finite clause subject introduced by just because (Bender \& Kathol 2005):

(42) Just because they use primitive means of doing things does not mean that they can't expand. (fe_03_06870A)

(43) Just because they say it doesn't mean that's the only way to look at it. (fe_03_00135A)

Clausal subjects are ordinarily introduced by that, not a subordinating conjunction like because, so we cannot use the general-purpose constituency rule that pairs a specifier with a head to account for the pattern in (42-43). Instead, as Bender \& Kathol argue, the grammar of English must contain an argument-structure construction that allows the verb mean, when negated, to license a clausal subject introduced by just because.

\subsubsection{Hypotactic Apposition}

When English speakers use a cataphoric demonstrative pronoun to announce forthcoming propositional content, they may do so by means of either the paratactic construction in (44) or the subordinating construction in (45-46), the latter of which Brenier \& Michaelis (2005) refer to as Hypotactic Apposition:

(44) That's what I've been telling you: you need to call.

(45) That's the problem is that they just hate us so much and I never re- I never really realized. (fe_03_01019A)

(46) That's the main thing is that I can't tell whether the thing is going to fit. (sw03729A)

In Hypotactic Apposition, the copula licenses two arguments that it would not license ordinarily: a clause containing a cataphoric pronoun and a clausal complement that is coreferential with the cataphoric pronoun contained in its clausal sister. This is not the licensing behavior of equational be, as found, e.g., in The problem is that they just hate us so much; it is the licensing behavior of the Hypotactic Apposition construction.

\subsubsection{Argument Quantification}

In quantifier-scope hierarchies, the quantifiers of topical and/or subject referents outscope those of nontopical and nonsubject referents (Ioup 1975, Kuno 1991). While these hierarchies capture robust cross-linguistic interpretive tendencies, they do not explain scope constraints in certain argument-structure patterns. The 


\section{Complementation by Construction}

two patterns that we will consider here are discussed in detail by Basilico (1998). They are the creation pattern, exemplified by (47) and the transformation pattern, exemplified by (48):

(47) Creation: She made a paperweight from a rock.

(48) Transformation: She made a rock into a paperweight.

In the Creation pattern either the theme argument or the source argument can have wide scope, as shown in (49-50):

(49) Wide scope theme argument: Every oak grew out of a tiny acorn.

(50) Wide scope source argument: An oak grew out of every acorn.

In the Transformation pattern, by contrast, the theme argument must scope the goal argument:

(51) Every acorn grew into a beautiful oak.

We know this because (52) is semantically anomalous, as indicated by \#:

(52) Wide scope theme argument: \#An acorn grew into every oak.

In (52), the theme argument is forced by the Transformation construction to have wide scope, and this creates a nonsensical sentence: we know that one acorn cannot produce many oaks. These scope facts cannot be said to follow from a semantic role hierarchy based on transconstructional relations like subject, because both the Creation pattern and the Transformation pattern map the theme argument to subject, as shown in (53-54):

(53) Creation: An oak grew out of an acorn.

(54) Transformation: An acorn grew into an oak.

Instead, the scope facts reflect the pragmatic role of the location argument in the Transformation pattern. The Creation pattern is pragmatically unmarked: it allows the source to be either topic or focus. This is shown in (55-56), where the points of prosodic prominence are indicated by small caps:

Topical source argument: An OAK grew out of it.

(56) Focal source argument: That oak grew out of an ACORN.

The Transformation pattern, by contrast, is pragmatically marked. Its goal argument is necessarily interpreted as focal, as indicated by the ungrammaticality of (58), in which the goal argument is expressed by a pronoun, versus (57), in which the theme argument is topical: 
The theme argument of the Transformation pattern is required to be a topic, as indicated by the ungrammaticality of (59):

Focal theme argument: *A tiny ACORN grew into that old oak.

As a topic, the theme argument of the Transformation construction cannot readily be interpreted as nonspecific; this follows from Lambrecht's Topic Acceptability Hierarchy (Lambrecht 1994: 165-171): topical arguments, as predictable arguments in predications, tend strongly to be mutually identifiable participants for the interlocutors. Because it allows a nonspecific interpretation, the theme argument of the Transformation pattern cannot take narrow scope relative to the goal argument; this leads to the anomaly in (52) above. To represent such constraints we have to be able to characterize the arguments licensed by verbs in terms of their pragmatic roles, e.g., topic and focus. This is something that we can do in the valence sets of argument-structure constructions, but not in Aktionsart representations.

Another interpretive phenomenon that points up the need for argument structures to supply quantification is one that I will call operator-free nominal coercion. Nominal coercion is reinterpretation of a nominal in order to resolve conflict between the type required by an operator and the type of the nominal argument supplied (Jackendoff 1997). For example, the English partitive article some induces the interpreter to construe the noun pillow as denoting a mass rather than a bounded entity in *some pillow. However, an operator-based model of nominal coercion only goes so far; it does not explain the interpretive effects evident in (60-61):

(60) Apple dries easily.

(61) You have apple on your shirt.

Neither dry nor have selects a mass-type second argument, so what can account for the portion or type reading of apple in these contexts? As discussed in section 2 above, arguments of verbs, whether phonetically instantiated or not, have to be quantified. This requirement is represented in SBCG by associating a quantifier frame with each of the verb's valence elements. In English, the primary means by which a common noun gets a quantified interpretation is through combination with a determiner. The only other way is through the Bare Noun Pumping Construction mentioned in section 2. As discussed there, this construction yields existentially and generically quantified interpretations of undetermined nouns. What triggers the use of this pumping construction? Simply put, it is the requirement that the nominal arguments of a predicator be quantified. Aktionsart representations do not contain quantifiers, but argument-structure constructions do. As 


\section{Complementation by Construction}

we saw in section 2, argument-structure constructions contain FRAMES among their semantic attributes. These frames include quantifier frames.

\subsection{Paradigmatic Effects}

Some combinatory constraints on argument-structures appear to be blocking effects. The frame [V PP] cannot express accompaniment to motion, but the frame [V X's way PP] can (Goldberg 1995, Croft 1991):

(62) She squinted *(her way) into the garden.

Another paradigmatic effect is override: when two constructions combine, one construction can override the constraints of another (Zwicky 1994). In this section, I will suggest that certain patterns of argument realization are due to the override of lexical valence by an argument-structure construction.

As RHL observe, activity verbs license indefinite null complements: eat, knit, sew, read. Such verbs allow indefinite null complements in episodic contexts:

(63) I ate at lunchtime

(64) Did you read yesterday?

Other verbs do not allow null complementation in episodic contexts; we can safely say of these verbs that they do not lexically license existential null complementation:

(65) We discussed *(some issues) last night.

(66) Did he impress *(people)?

(67) They destroyed *(things).

(68) Did they serve *(things) cold?

But certain syntactic contexts can change verb affordances (Ruppenhofer 2004, this volume):

(69) Existential perfect: She has always impressed (people). Have you stolen (things) from me?

(70) Habitual: They discuss and discuss (things) but never seem to do anything. They destroy (things) and we rebuild (them).

(71) Generic: Speed kills (people).

(72) Instructional, Imperative: Heat (the item) thoroughly. Lift (this)!

(73) Sentence focus in fictive-motion predications: Even though a major ROAD goes by (there), no one disturbed me while I was taking photographs.

The fact that verbs' argument-realization requirements can be overridden by context shows again that a verb's syntactic frame is not determined solely by its 
lexical entry, derived or basic; instead, it is determined by the construction with which it combines.

\section{Supporting evidence from frame-based speech errors}

How are verb frames accessed? Influential psycholinguistic studies have proposed that access is incremental: each denotatum is assigned a grammatical role in the order that its discourse-salience dictates; for example, the discourse topic gets the subject role (Ferreira 1996, Bock \& Levelt 1994). A competing model is competitive access, whereby functional relations are accessed as sets, in much the same way that lexemes are accessed. Clearly, a construction-based model of argument structure entails competitive access, and, as it happens, certain syntactic speech errors, called syntactic splices, suggest that verb-frame access is indeed competitive (Raymond 2000). Why? First, many error frames involve dummy elements, as in the following attested examples:

(74) When you consider the greatest good, it's just better off to let them [children] do stuff. (Presumed target: They're just better off if ...)

(75) It's glad you've marshaled your evidence. (Presumed target: I'm glad that...)

If grammatical-function assignment relies on the relative discourse salience of an array of referents, there is no obvious explanation for the existence of splices like (74-75). If, however, verb-frame access is competitive, these examples are simply the result of failure to suppress the undesired frame. Second, many frame errors don't involve the incorrect encoding of any given argument but are instead amalgams of two incompatible sentence patterns:

(76) Raising spliced with extraposition: They seem they know where the problem is.

(77) Relative clause spliced with conjunction: To what extent am I responding to errors that I'm not conscious of it?

(78) VP ellipsis spliced with conjunction: She was severely injured as well as her assistant was too.

The dual encoding of a single argument, e.g., they in (76), suggests that the speaker, rather than choosing the wrong grammatical encoding for the currently active referent, or the wrong verb, has simply superimposed one chunk of structure on top of another in the same way that she might output the error word troublematic by failing to suppress either troublesome or problematic. So syntactic speech errors lend some support to the constructionist's claim that words and syntactic patterns are stored in the same place and processed in the same way (Bates \& Goodman 1997). 


\section{Complementation by Construction}

\section{Conclusion}

The evidence that we have reviewed here suggests that verbal argument structure is not derived from or 'read off' semantic representation. Verbs license the arguments that they do because they combine with constructions that (a) determine how each scene participant will be expressed syntactically, (b) provide quantifiers for each argument and (c) sometimes determine which argument will be topic and which focus. On this approach, semantic roles exist only in theta frames (e.g., causation of result and caused motion); there is no semantic role hierarchy of the type used to assign grammatical functions in most current accounts of argument structure, including RHL. As Fillmore \& Kay (1995) point out, the semantic role hierarchy, despite its widespread currency, is a poor candidate for a linguistic generalization because it features combinations of semantic roles that no verb would ever license. Theta frames, by contrast, express only those semantic role sets that play a role in verb-valence descriptions. But no language user ever encounters a naked theta frame: the generalizations about semantic role combinations that speakers learn and use are theta frames as expressed by morphosyntactic patterns, and these morphosyntactic patterns, as we, have seen contain a good deal of idiomatic information about meaning, use and form. In sum, the study of verbal argument licensing, like Bybee's studies of the inflectional morphology (Bybee 2001), could be said to demonstrate that linguistic generalizations are simply not that general.

\section{References}

Basilico, David. 1998. Object Position and Predication Forms. Natural Language and Linguistic Theory 16:491-539.

Bates, Elizabeth and Judith C. Goodman. 1997. On the Inseparability of Grammar and the Lexicon: Evidence from Acquisition, Aphasia and Real-time Processing. Language and Cognitive Processes 12:507-584.

Bender, Emily and Andreas Kathol. 2005. Constructional Effects of Just Because...Doesn't Mean... In C. Chang, M. Houser, Y. Kim, D. Mortensen, M. Park-Doob and M. Toosarvandani eds., Proceedings of the Twenty-Seventh Annual Meeting of the Berkeley Linguistics Society. Berkeley, CA: Berkeley Linguistics Society.

Birner, Betty J. and Gregory Ward. 1998. Information Status and Noncanonical Word Order in English. Amsterdam/Philadelphia: John Benjamins.

Bock, Kay and Willem Levelt. 1994. Language Production: Grammatical Encoding. In M.A. Gernsbacher, ed., Handbook of Psycholinguistics, 945-984. San Diego, CA: Academic Press.

Brenier, Jason M. and Laura A. Michaelis. 2005. Optimization via Syntactic Amalgam: Syntax-Prosody Mismatch and Copula Doubling. Corpus Linguistics and Linguistic Theory 1:45-88. 
Bresnan, Joan. 1994. Locative Inversion and the Architecture of Universal Grammar. Language 70:72-131.

Bybee, Joan. 2001. Phonology and Language Use. Cambridge: Cambridge University Press.

Chierchia, Gennaro. 2003. Language, Thought and Reality after Chomsky. Ms. University of Milan-Bicocca.

Croft, William. 1991. Syntactic Categories and Grammatical Relations. Chicago: University of Chicago Press.

Ferreira, Victor 1996. Is it Better to Give than to Donate? Syntactic Flexibility in Language Production. Journal of Memory and Language 35:724-755.

Fillmore, Charles J. 1986. Pragmatically Controlled Zero Anaphora. BLS 12:95107.

Fillmore, Charles J. and Paul Kay. 1995. Construction Grammar. Unpublished ms., University of California, Berkeley.

Fillmore, C. J., P. Kay, L. A. Michaelis and I. A. Sag. forthcoming. Overt and Covert Nominals in English: A Constructional Approach. Stanford: CSLI Publications.

Goldberg, Adele. 1995. Constructions: A Construction Grammar Approach to Argument Structure. Chicago: University of Chicago Press.

Goldberg, Adele. 2001. Patient Arguments of Causative Verbs can be Omitted: The Role of Information Structure in Argument Distribution. Language Sciences 23:503-524.

Goldberg, Adele. 2002. Surface Generalizations: An Alternative to Alternations. Cognitive Linguistics 13:327-356.

Goldberg, Adele. 2005. Constructions, Lexical Semantics and the Correspondence Principle: Accounting for Generalizations and Subregularities in the Realization of Arguments. In N. Erteschik-Shir and T. Rapoport, eds., The Syntax of Aspect, 212-236. Oxford: Oxford University Press.

Goldberg, Adele. 2006. Constructions at Work: The Nature of Generalization in Language. Oxford: Oxford University Press.

Ioup, Georgette. 1975. Some Universals for Quantifier Scope. In J. Kimball, ed., Syntax and Semantics 4:37-58. New York: Academic Press.

Jackendoff, Ray. 1997. The Architecture of the Language Faculty. Cambridge, MA: MIT Press.

Kaschak, Michael and Arthur Glenberg. 2000. Constructing Meaning: The Role of Affordances and Grammatical Constructions in Language Comprehension. Journal of Memory and Language 43:508-529.

Kaschak, Michael and Arthur Glenberg. 2002. Grounding Language in Action. Psychonomic Bulletin and Review 9:558-565.

Kuno, Susumo. 1991. Remarks on Quantifier Scope. In H. Nakajima, ed., Current English Linguistics in Japan, 261-287. Berlin: Mouton de Gruyter.

Lambrecht, Knud. 1994. Information Structure and Sentence Form. Cambridge: Cambridge University Press. 


\section{Complementation by Construction}

Levin, Beth and Malka Rappaport Hovav. 1995. Unaccusativity. Cambridge, MA: MIT Press.

Michaelis, Laura A. 2004. Type Shifting in Construction Grammar: An Integrated Approach to Aspectual Coercion. Cognitive Linguistics 15:1-67.

Levin, Beth. 2000. Aspect, Lexical Semantic Representation and Argument Expression. BLS 26: 413-429.

Michaelis, Laura A. and Josef Ruppenhofer. 2001. Beyond Alternations: A Construction-Based Approach to the Applicative Pattern in German. Stanford: CSLI Publications.

Michaelis, Laura A. and Knud Lambrecht. 1996. Toward a Construction-Based Model of Language Function: The Case of Nominal Extraposition. Language 72:215-247.

Moens, Marc and Mark Steedman. 1988. Temporal Ontology and Temporal Reference. Computational Linguistics 14:15-28.

Partee, Barbara H., and Vladimir Borschev. 2007. Existential Sentences, BE and the Genitive of Negation in Russian. In K. von Heisenger and I. Comorovski, (eds.), Existence: Semantics and Syntax. Berlin: Springer Verlag. 147-190

Pinker, Steven. 1989. Learnability and Cognition. Cambridge, MA: MIT Press.

Rappaport Hovav, Malka and Beth Levin. 1998. Building Verb Meanings. In M. Butt and W. Geuder, eds., The Projection of Arguments, 97-134. Stanford: CSLI Publications.

Raymond, William D 2000. Toward a Theory of Grammatical Encoding in Speech Production: Evidence from Speech Errors. Ph.D. diss., University of Colorado at Boulder. [University of Colorado Institute of Cognitive Science Technical Report 01-01]

Ruppenhofer, Josef. 2004. The Interaction of Valence and Information Structure. $\mathrm{Ph}$.D. diss., University of California, Berkeley.

Ruppenhofer, Josef. this volume. Fictive Motion and Null Instantiation.

Zwicky, Arnold. 1994. Dealing out Meaning: Fundamentals of Grammatical Constructions. BLS 20: 611-25.

Laura Michaelis

Department of Linguistics

University of Colorado

295UCB

Boulder, CO 80309

michaeli@colorado.edu 